Journal of Teacher Education for Sustainability, vol. 21, no. 1, pp. 35-47, 2019

\title{
Detecting a Sustainable Mindset through Using Content Analysis of Teacher-produced Learning Journals
}

\author{
Anne E. M. Fox \\ Norwegian University of Science and Technology (NTNU), Trondheim, Norway \\ Sandra Iriste \\ Latvia University of Life Sciences and Technologies, Jelgava, Latvia \\ Petra Bezeljak \\ University College for Agrarian and Environmental Pedagogy, Vienna, Austria
}

\begin{abstract}
Having developed and piloted a professional development blended learning course for teachers of home economics with the purpose of promoting a sustainable mindset in their students, we used the written learning journals by the teachers during the 15 -week course to detect various aspects of a sustainable mindset, which could be attributed to the course. We assumed that the learning journals of 19 participants might reveal reflections on sustainability, the pedagogy of sustainability, a positive association between sustainability and the pedagogy of sustainability, and the development of a sustainable mindset over the period of the course. The analysis confirmed that the participants reflected a great deal on learning and sustainability as the course progressed; revealing that a positive link between teaching practice and sustainability can be observed. However, the analysis also indicated some important concepts that might have been underemphasised in the course.
\end{abstract}

Keywords: sustainable mindset, blended learning course, home economics teachers, learning journals, strong sustainability.

\section{Introduction}

It was during 2018 that 35 teachers, who were recruited globally, participated in a teacher training course offered by the ProfESus European project. With the aim of 'discovering a sustainable mindset for future-oriented professionals in guest-oriented businesses', the project was to enable home economics teachers to train their students to adopt sustainable practices. The main intention was to help the students of these teachers to spread sustainable home economics practices into their personal and future working lives. The course was blended, consisting of an introduction, called Module 1, 
which included face-to-face discussions over a week in Austria, followed by Module 2 that comprised 7 units over 8 weeks exploring how selected approaches such as case studies and transformative pedagogy could promote competency in sustainable work practices. Moreover, there was also Module 3, which was another online module with the purpose of planning and executing a lesson or series of lessons over 5 weeks. Finally, Module 4 was designed in which the last face-to-face discussions were run during a week in Finland. In Module 4, the participants assessed their lesson projects and made plans for their future classroom practice. A central aim of the course was to promote a sustainable mindset both in the teachers and their students.

Learning journals were used as a part of 8 ECVET/ECTS credit course (ProfESus, online) for several reasons. One main reason is that the journals can be sources of feedback on the quality of the pilot course. Furthermore, one pedagogical reason for asking the teachers to complete the learning journals is that they can be of great value to the teachers when they are thinking of implementing new methods (Bashan \& Holsblat, 2017; Butcher \& Eldridge, 1990; Coll \& Coll, 2018; Wallin \& Adawi, 2018). Additionally, one more reason for employing learning journals as a part of the learning strategy, in the current study, was to reveal a sustainable mindset in our teacherparticipants and their students. The value of using teacher reflection journals to discern sustainable values and dispositions specifically has also been shown by using manual coding methods (Khazaeenezhad, Tavakoli \& Amirian, 2018). Since a mindset is an abstract term, we predicted that the journals would both prompt and reveal the depth and nature of our learners' sustainable mindsets.

When delving into the concepts of teacher training courses, one can figure out that the three central concepts in the ProfESus teacher training course are green pedagogy (Forstner-Ebhart \& Linder, 2017; UCAEP, 2018; Wogowitsch, 2013), sustainability competencies (Fuertes-Camacho et al., 2019; Lambrechts et al., 2013; Ploum et al., 2018; Rauch \& Steiner, 2013), and strong sustainability (Holt, 2012, Ikerd et al., 2014, Starchan, 2009; Sterling, 2004; Sterling 2001). These concepts were combined in a sustainable mindset. Green pedagogy is a kind of pedagogy developed by the University College for Agricultural and Environmental Pedagogy (Wogowitsch, 2013) in Vienna. It is mostly written about in German, to date. The sustainability competencies are based on the standard definition of competencies as comprising knowledge, skills, and attitudes in which the attitude component is further subdivided into personal attitudes, as revealed by values, and ability and willingness to collaborate (Rauch \& Steiner, 2013). This four-dimensional model of competence is implemented in the work of the United Nations in sustainability. It is best exemplified by the UNECE competencies (UNECE, 2011). Strong sustainability refers to embedded practice of sustainable competencies during scheduled learning activities showing understanding that the benefits of nature are irreplaceable and that the entire economy is reliant on society, which, in turn, is entirely dependent on the environment. Hence, in examining the learning journals of our teacherparticipants, we were expecting to find evidence of all three of these central concepts.

To conduct this study, we used the Leximancer content analysis software which automatically processes any text corpus fed into it. The software goes beyond counting of keywords as it is analysing which concepts are close in meaning in order to create multi-word thesaurus categories and determine their relative importance. The software also analyses how closely linked each concept is to every other significant concept in the corpus. It should, therefore, be able to reveal in an impartial manner how the concepts 
which are written about in the learning journals are connected to each other; moreover, whether this is a negative or positive connection. This software has been previously used to analyse learning diaries (Letch, 2012). We judged that the automation inherent in the software would overcome any bias which might occur if we hand-coded the text as is necessary when using a tool such as NVivo. This distance was required since the authors were heavily involved in the development and supervision of the course under investigation. Given the features of the software, we thought that it could be used to answer the following questions which are in an increasing order of complexity:

1. Does the ProfESus course lead its participants to reflect on sustainability?

2. Does the ProfESus course lead its participants to reflect on the pedagogy of sustainability?

3. Does the ProfESus course lead its participants to reflect positively on sustainability?

4. Does the ProfESus course lead its participants to reflect on strong sustainability that increases over the lifetime of the course?

We believed that by obtaining responses to these questions, the developers of the ProfESus course could improve its quality.

\section{Methodology}

The ProfESus course is a 15 -week and four-module blended learning course in which participants, mostly teachers or student-teachers, are required to keep learning journals for the first 14 weeks (representing nine entries and three modules). The corpus used in this analysis draws on the learning journals of 19 participants, not all of whom completed journals for the whole 14-week period but they completed at least seven out of the nine main required entries. Thirty-five participants enrolled on the course, and of those, 24 completed the course, and 19 both submitted at least seven journal entries and gave permission to use the texts. It is worth mentioning while nine entries covered three of the four modules, seven entries covered at minimum seven weeks of the 15 weeks mostly centred on Module 2, an exploration of sustainable pedagogies and how these support the main issues of sustainable development related to home economics. Participants were guided in what to write about in their learning journals with questions relating to the module or unit it was included in. However, participants were always free to write about whatever they thought was relevant. The learning journals were not visible to the other course participants, only to tutors; hence, they were relatively private and could be expected to reflect participants' honest opinions. Some examples of the prompts that participants were given for writing their learning journals are shown below. It relates to Unit 2.5 of Module 2 which focused on strategic thinking. Once again, it should be noted that the participants were free to respond to as many or as few of the prompts as they wished.

You tried out the Zero Waste Challenge. Reflect on how this made you feel, your successes and failures and what strategies you found were most effective.

Think about the value of an eco-labelling exercise for your students either based around your own institution or based on investigating local hospitality organisations. What benefits would there be for your students? 
Have you tried anything out or altered your practice either in your private, professional or pedagogical activities as a result of something you learned in this unit?

Describe any ideas this unit has given you for your Module 3 project.

The type of data analysed by using the Leximancer software was the text which the participants wrote in their learning journals. Videos and images were omitted as was the response of tutors to the learning journal entries. Furthermore, the copied texts from elsewhere were excluded. As an example, many participants copied the learning activity plan template into their journals at some point and these types of copied texts were excluded from the analysis so that what remained was entirely the participants' own words. The participants were not limited regarding the text length, but they were generally advised to spend about an hour on preparing their journal entry. Therefore, the length of each entry varied widely. On average, however, the length was about two or three paragraphs for each entry.

The set of learning journals used in the analysis could be easily delineated according to the participants and the distance into the course that each learning journal entry related to. The Leximancer tool was used to determine whether a sustainable mindset could be inferred from the learning journals.

\section{Limitations of Using Text Analysis}

We used the Leximancer text mining software to analyse the content of the learning diaries. One challenge in this regard was that except for one of the participants, all were using English as a Second Language. Therefore, English was not always used correctly as for example grose was used instead of gross. In preparing the texts for analysis, the researchers corrected the obvious spelling errors or abbreviations so that the software did not overlook related concepts. The most common example was 'SUS' which was often used in place of sustainable or sustainability. It should be noted that three of the participants included images and videos in their learning diaries which were omitted during the analysis since the software is not able to process other media except for written texts. However, since the participants used text overwhelmingly in their learning diaries, it was not considered that a great deal was lost by this omission.

It is possible for the Leximancer software to give slightly different results from the same corpus of texts, so care must be taken not to over-analyse the results. This variation is not significantly greater than the coder differences when content analysis is performed manually (Sotiriadou, 2014).

\section{Results and Discussion}

The first research question which was addressed was "Does the ProfESus course lead its participants to reflect on sustainability?"

Since the aim of the course was to prompt teachers of home economics to embed sustainable work practices in their students, we would expect that participating in the ProfESus course would lead to much reflection on the concept of sustainability and related concepts. 
When processing a corpus of text through the text mining software, the first result is an automatically generated list of the main themes included in the corpus and a map showing how the themes are linked. The map for the complete collection of eligible learning journals is shown below in Figure 1.

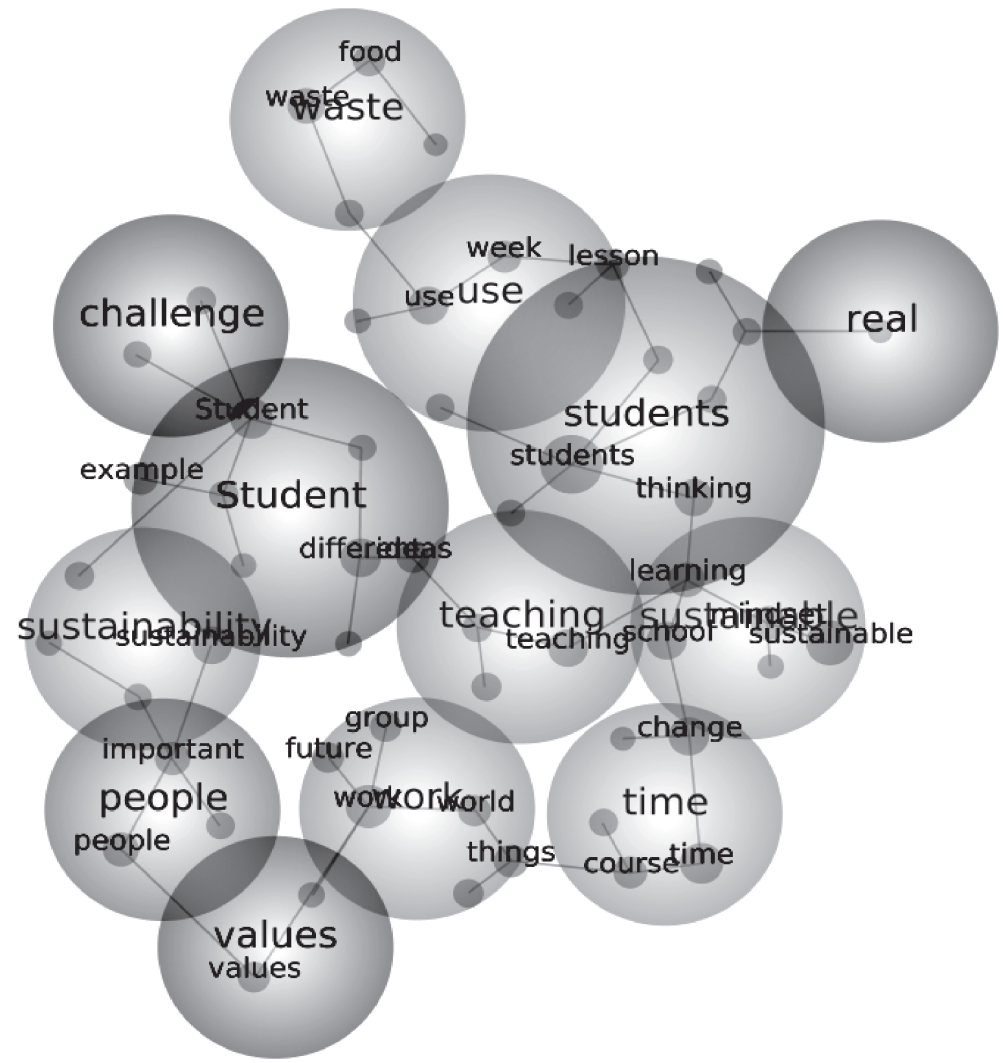

Figure 1. The map of themes (large text) and concepts (smaller text) generated by the learning journal texts

The software identified 55 concepts composing thirteen overall themes. Since the participants are teachers, student-teachers or trainers, it is not surprising that the most frequently used concepts include students, time, school, teaching and course. There are 5 sustainability related concepts in the top 20 concepts including sustainable, sustainability, waste, food and values.

This is a result which we would not expect in a random collection of learning journals for educators not selected for sustainability. We can compare these results to a similar processing in the same software of three documents that are specifically related to sustainability education, namely "Future Fit" (Sterling, 2012), "Learning for the Future" (UNECE, 2011), and the English version of "Green Pedagogy" (UCAEP, 2018) that were key texts used in the ProfESus project on the topic of sustainable education pedagogy. Comparing the top 20 key concepts of the learning journals to the top 20 concepts in the three key texts, one can observe that eight key concepts appear in both lists, and of those only two, sustainable and sustainability, are directly connected to the 
main aim of the course. However, the two lists are clearly concerned with teaching and learning, even if the dominant concepts are expressed differently, such as course in the learning journal concept list and education in the key text list. The comparison indicates that the participants of the ProfESus course were writing about sustainability to the same degree when compared to the authors of our key texts. Therefore, we can conclude that the course did lead to the participants' engaging in the idea of sustainability.

The second question which was addressed was "Does the ProfESus course lead its participants to reflect on the pedagogy of sustainability?" The main theme map generated by the Leximancer tool in Figure 1 illustrates a very strong focus on learning connected with sustainability, i.e. all concepts are related either to learning or to sustainability and nothing else. The largest and reddest sphere indicates the strongest theme of the corpus, which in this case, is students. The distance between each sphere shows how tightly or loosely connected each concept is to the others identified. Thus, time is tightly connected to sustainability, but it is very loosely connected to the concept of waste. We speculate that this means that teachers feel they lack time to implement sustainable solutions and the software can confirm this by running a query to find out examples in the texts where the concepts of time and sustainability were used in close proximity. Examples 1 and 2 demonstrate this issue.

Example 1

There is not enough time to teach core elements integrating sustainability.

Example 2

Only because the amount of the time I have to teach sustainability is very limited.

The next step is to find out if the concepts of sustainability and learning are strongly linked. Sustainability in the context of education and pedagogy is the focus of the course. We start by exploring what the concepts of sustainable and sustainability are most strongly linked to. Choosing sustainable as a concept, we find seven of the concepts associated with sustainable which are associated unequivocally to education and learning. Those concepts are teaching, teachers, students, course, education, school and learning, while another three are most likely to relate to an educational context: thinking, idea, topic. There is a possible connection to other sustainable topics such as world, change, better, future and environment. The most noteworthy result of this search is that the most tightly connected concept with sustainable is mindset (see also Figure 1). This is a clear indication that the course has succeeded in linking the topic of sustainability with the need for competence in sustainability to be connected to a mindset. This was a major aim of the course, i.e. the knowledge of sustainability is not sufficient on its own but must be accompanied by an associated mindset. Finally, we can check the connections in these areas by looking at extracts from the learning journal texts that were deemed by the software to link the two concepts. If we take teaching as an example of a clear educational concept, then, here is an instance of where the concept of teaching was linked to the concept of sustainable.

\section{Extract 1}

I'm constantly considering whether sustainable development has been taken into account in teaching enough? 
We can also see how sustainable and mindset occurred together.

Extract 2

The man who showed us the rooms was a good role model of having a sustainable mindset or act like having it.

We can test whether the high ranking of thinking in association with sustainable is educational or not.

\section{Extract 3}

Anyway, sustainable thinking seems to be all over, wherever I go.

Therefore, the participants did write about sustainability in relation to learning. We can examine whether this is a definite link to show that they were reflecting on the pedagogy of sustainability by analysing a few more sustainability concepts from the map of main themes. The specific concept of sustainability shows a tighter connection to pedagogical concepts. As with the concept of sustainable, the concept of sustainability is closely linked to teaching and learning. Two of the concepts associated with sustainability related unequivocally to education and learning: teacher and course, while another five are most likely to relate to an educational context: thinking, idea, project, group and topic. In addition, there are a few concepts directly linked to sustainability, including future, world and better. The following extract shows an example of how sustainability is linked with teacher.

Extract 4

For me this is what sustainability is all about. It has the 3 pillars in it, as a teacher or studying to become an educator you have to understand and want to live sustainably.

In the ProfESus project, we emphasised the importance of sustainable competencies to indicate that it was important to consider not just knowledge about sustainability but also skills and attitudes, the latter divided into collaborative skills and personal values, to implement sustainability. We used the concept of competence as defined by UNECE (2011). This definition and the fact that the ProfESus course was called 'discovering a sustainable mindset' made it relevant to examine the two concepts of values and mindset as relevant results from the content analysis.

\section{Values}

The concept of values is one of the main themes in the learning journals with 92 hits which shows that the message that sustainability is not just about knowledge has broken through. Values are important components of the sustainable competency model applied in the ProfESus course (the others being knowledge about sustainability, sustainable skills and collaborative abilities). Consequently, this shows that evidence of the necessity for sustainable competencies is visible, but we do not know the extent to which the full competency model has been embedded. Extract 5 shows this issue.

\section{Extract 5}

Therefore, despite the conflict, I believe no matter what personal/individual values reflect, everyone still has an opportunity and a role to play towards promoting sustain- 
ability related issues and practices. It is also good that members get to know and understand their values.

\section{Mindset}

The concept of mindset is critical to training students to act sustainably by default. The concept mindset occurs most often in connection with sustainable and, secondly, with the word change and several times in connection with teaching and learning. Extract 6 indicates the connection.

\section{Extract 6}

This week I have taken part in many discussions about zero-waste goal and about sustainable mindset vision.

This is encouraging as it supports the conclusion that sustainability has been successfully linked with the importance of mindset in the minds of the participants. Thus, a closer examination of the four most prominent sustainability concepts shows its close association with pedagogical concepts. Moreover, it demonstrates that the two themes have been linked in the learning journals.

The third research question which was addressed was "Does the ProfESus course lead to positive reflection on sustainability?" It is difficult to interpret the results of the sentiment analysis in the content analysis tool because there are several favourable and unfavourable interpretations. In a learning diary, individuals can be positive or negative about the course. Moreover, they can also be positive about the increasing feeling of agency in the face of intractable sustainability challenges. It is conceivable that individuals can be positive about the course and negative about their ability to effect change in favour of sustainability. It is possible, but unlikely, that somebody will be negative about the course but positive about his/her ability to effect change in favour of sustainability. The most likely outcome if you were feeling negative about the course would be to drop out at an early stage. There were dropouts on several grounds, including insufficient time, lack of confidence in using the course technology, and lack of formality. A few of the participants were committed to the course as a part of their degree and they could have been negative, but they continued. However, the majority of the participants that completed the course did so because they thought it was worthwhile.

The analysis shows a strong favourable sentiment (255 instances) and a low unfavourable sentiment (74 instances) across the 19 learner journals. The following examples are favourable and unfavourable comments:

Extract 7

Changing body and cleaning products to eco-friendlier alternative because you don't want to harm yourself is a good thing. Small steps count (favourable)

\section{Extract 8}

I have a very open classroom where the pupils are free to disagree and discuss all topics. But starting with provocation is perhaps a good way to get attention (favourable)

\section{Extract 9}

They want to create an end plastic pollution in XXX. I see this problem first hand here on our beach (unfavourable). 


\section{Extract 10}

Consumers are being 'forced' to shop and therefore accept supermarket policies, however ridiculous they might be. Multi-buy offers and XXL packs are becoming an everyday part of shopping (unfavourable).

It seems that the unfavourable comments are not directed at the course, but they are directed at seemingly unsolvable sustainability problems. Extract 11 shows a failure in the classroom that can be used by the students as a positive learning point while extract 12 reflects on the course participant's colleagues.

\section{Extract 11}

So there was too much sugar in the dough that it burned in to the waffle-iron. This was an example of a failure, from which the pupils did learn in action why to go with the recipe, at least mostly.

\section{Extract 12}

Areas which are difficult to change? The narrow-mindedness and inability to think outside the box amongst some of my colleagues can sometimes be frustrating.

Hence, it seems that even the unfavourable comments can be seen as positive for the course. Of the 74 extracts, only three were mild criticism of the course. Extract 13 is an example of such mild criticism.

\section{Extract 13}

I did enjoy this group work and activity, but just had one critique. While I do think it is great to think of the negative and what can go wrong, it is also very important to find solutions.

One of the important concepts of green pedagogy is that students should also work towards realistic solutions, so this critique was addressed in the course at a later stage.

We can therefore say that there is a strong positive association between sustainability and educational concepts as a result of the ProfESus course although the exact nature of this positive mood is less clear.

The final question which was addressed in the current study was "Does the ProfESus course lead to deeper reflection on sustainability over the lifetime of the course?" This question can be answered by examining how the main concepts changed over time through comparing journal entries in the early stages of the course (Figure 2) to those from the end of the course (Figure 3). The course stretched over 15 weeks, but the journals covered only the first 14 , so they did not catch the end of the course nor what the participants implemented after the course. 

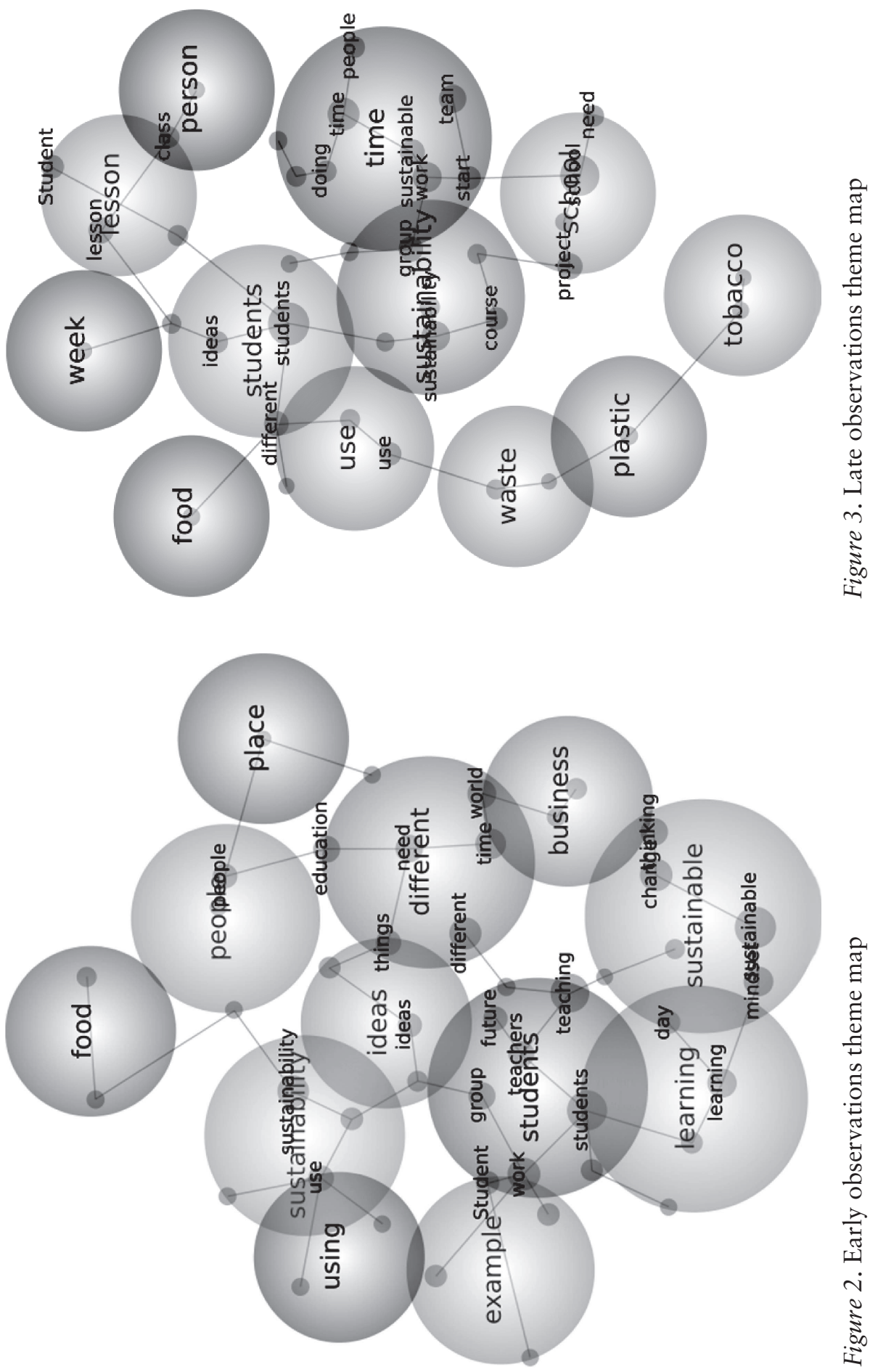
There are clear differences in the main theme maps at the early stages of the course compared to the late stages. This may simply reflect different course content at each stage. By the late stage of the course, the participants seemed to be more concerned with specific aspects of sustainability such as plastics and waste, whereas at the beginning they were more concerned with the differences that were presented to them in terms of everyday processes, pedagogy and organisations. This shows a more nuanced understanding of the concept of sustainability over time although it does not provide evidence of an actual increase in sustainable behaviour. Food is a common theme, both at the start and at the end of the course, but looking at the diary extracts shows that there were differences at the start and the end of the course. At the start of the course, food was mentioned as a general world problem, in terms of personal attitudes or in relation to some of the visits that were included in Module 1 in Vienna. At the end of the course, food was most often mentioned in relation to specific learning activities. Examining the themes at the end of the course shows that the concepts of plastic, tobacco, waste and food are all mentioned in relation to a specific lesson, training idea or community initiative. A 15 -week course is most likely not long enough to promote strong sustainability based on competence, but these are clear signs of steps in the right direction.

\section{What is Missing?}

The ProfESus course recommends Green Pedagogy as a useful approach to ensure that sustainability is embedded in learners' everyday practice, but the concept does not appear in the content analysis of the learning journals as an important theme. The concept of Green Pedagogy was identified by the software, but was not mentioned sufficiently often for it to figure in the list of twenty most important concepts. Moreover, another missing point is any major reference to the UNECE competencies, which form the backbone of the planning template of the learning activities. The participants were recommended to use these learning activity plans in their trial lessons. Since learning activities were supposed to be centred on specific home economics competencies, and the assessment of what students do in the lessons should be based on progress towards sustainability competencies, then this is surprising and may point to a need to adjust the ProfESus course materials so that these important concepts come over more clearly to the teacher course participants.

\section{Conclusion}

Analysing the content of the participant learning journals shows that the ProfESus course has succeeded in raising awareness of sustainability and associating this with pedagogy. However, a strong awareness of Green Pedagogy fails to manifest, as do the UNECE sustainability competencies. A textual analysis of the course materials should be done to see if these concepts are given their due prominence. However, an indicator of sustainability awareness is observable through the high ranking of the concept of values, a subset of the UNECE competencies, and the concept of mindset. The presence of a concept, especially at a high rank, is likely good evidence that the concept has true significance in the context of the analysis, in this case, learning journals of teachers wishing to implement a more sustainable pedagogy. 
The absence of a concept is more difficult to interpret. The software may be less likely to identify competencies as a concept and the appearance of values, a subset of the ProfESus concept of sustainable competencies, may indicate that our promotion of the UNECE competency framework succeeded to a greater extent than the Leximancer software shows. The analysis demonstrates a high level of favourable (as against unfavourable) content and once the few instances of unfavourable content is examined, it is apparent that this deals with common teaching challenges of lack of time or unsupportive colleagues as well as the overwhelming nature of some sustainability goals rather than feelings of discontent with the course or the philosophy of the course. The text analysis is less useful in showing increased sustainability awareness over time. This question may be better answered using other methods. That said, we conclude that teacher learning diaries are a rich source of feedback on the efficacy of the course and can be used as a part of the quality assurance process to improve the course.

\section{References}

Bashan, B., \& Holsblat, R. (2017). Reflective journals as a research tool: The case of student teachers' development of teamwork. Cogent Education, 4, 1-15.

Butcher, R., \& Eldridge, J. (1990). The use of diaries in data collection. The Statistician, $39(1), 25-41$.

Coll, S. D., \& Coll, R. K. (2018). Using blended learning and out-of-school visits: Pedagogies for effective science teaching in the twenty-first century. Research in Science and Technological Education, 36(2), 185-204. https://doi.org/10.1080/02635143. 2017.1393658

Forstner-Ebhart, A., \& Linder, W. (2017). Grüne Pädagogik - Lernen am Widerspruch [Green Pedagogy - Learning through Contradiction]. Open Online Journal for Research and Education. Research Day, April 2017. [online] Available at https://journal.ph-noe.ac.at/index.php/resource/article/view/358

Fuertes-Camacho, M. T., Graell-Martin, M., Fuentes-Loss, M., \& Balaguer-Fabregas, M. (2019). Integrating sustainability into higher education curricula through the project method, a global learning strategy. Sustainability, 11(3), 1-25. https:/doi.org/ 10.3390/su11030767

Holt, D. B. (2012). Constructing sustainable consumption: From ethical values to the cultural transformation of unsustainable markets. The Annals of the American Academy of Political and Social Science, 644(1), 236-255. https://doi.org/10.1177/ 0002716212453260

Ikerd, J., Gamble, L., \& Cox, T. (2014). Deep sustainability: The essentials. [online] Available at https://sites.google.com/site/sustainabilitydeep/

Khazaeenezhad, B., Tavakoli, M., \& Amirian, Z. (2018). Making sense of core qualities to sustain professional development through core reflection practice. Journal of Teacher Education for Sustainability, 20(1), 93-105. https://doi.org/10.2478/jtes2018-0006

Lambrechts, W., Mula, I., Ceulemans, K., Molderez, I., \& Gaeremynck, V. (2013). The integration of competences for sustainable development in higher education: An analysis of bachelor programs in management. Journal of Cleaner Production, 48, 65-73. https://doi.org/10.1016/j.jclepro.2011.12.034 
Letch, N. (2012). Using reflective journals to engage students in learning business process management concepts. Knowledge Management \& E-Learning: An International Journal, 4(4), 435-454.

Leximancer software. Available at https://info.leximancer.com/

Ploum, L., Blok, V., Lans, T., \& Omta, O. (2018). Toward a validated competence framework for sustainable entrepreneurship. Organization and Environment, 31(2), 113-132. https://doi.org/10.1177\%2F1086026617697039

ProfESus Erasmus+ project. Link to curriculum https://profesus.eu/outputs/english/

Rauch, F., \& Steiner, R. (2013). Competences for education for sustainable development in teacher education. CEPS Journal, 3(1), 9-24.

Sotiriadou, P., Brouwers, J., \& Le, T. (2014). Choosing a qualitative data analysis tool: A comparison of NVivo and Leximancer. Annals of Leisure Research, 17(2), 218234.

Starchan, G. (2009). System thinking: The ability to recognise and analyse the interconnections within and between systems. In A. Stibbe (Ed.), The handbook of sustainability literacy (pp. 84-88). Dartington: Green Books.

Sterling, S. (2004). Higher education, sustainability, and the role of systemic learning. In P. B. Corcoran \& A. E. J. Wals (Eds.), Higher education and the challenge of sustainability (pp. 49-70). Dordrecht: Springer.

Sterling, S. (2001). Sustainable education: Re-visioning learning and change. Dartington: Schumacher Society, Green Books.

Sterling, S. (2012). The Future fit framework: An introductory guide to teaching and learning for sustainability. Plymouth: Higher Education Academy.

UCAEP. (2018). Green pedagogy: From theoretical basics to practical sustainable learning activities. Vienna: Vizerektorat für Umweltpädagogik, Weiterbildung und Forschung.

UNECE. (2011). The competences in education for sustainable development (learning for the future: competences in education for sustainable development). (2011, 7 April). [online] Available at https://www.unece.org/fileadmin/DAM/env/esd/ ESD_Publications/Competences_Publication.pdf

Wallin, P., \& Adawi, T. (2018). The reflective diary as a method for the formative assessment of self-regulated learning. European Journal of Engineering Education, 43(4), 507-521. https://doi.org/10.1080/03043797.2017.1290585

Wogowitsch, C. (2013). Methoden für kreative Lernprozesse [Methods for creative learning processes]. In C. Wogowitsch (Hrsg.), Grüne Pädagogik - vom Theoriefundament bis zu professionsorientierten Lernarrangements [Green Pedagogy From theoretical foundations to professional learning practices] (pp. 44-50). Wien: Hochschule für Agrar- und Umweltpädagogik.

Correspondence concerning this paper should be addressed to Anne E. M. Fox, Assistant Professor, Department of Computer Science, NTNU (Norwegian University of Science and Technology), Høgskoleringen 1, 7491 Trondheim, Norway. Email: anne.e.m.fox@ntnu.no 